\title{
Aerodynamic Drag Reduction of Vehicle Si Pitung G4 UNJ for Shell Eco-Marathon Asia 2015
}

\section{Sirojuddin¹, Raden Engineu ${ }^{2}$, and Wardoyo ${ }^{1}$}

${ }^{1}$ Vocational Educational Program of Mechanical Engineering, State University of Jakarta

${ }^{2}$ Design Laboratory of Vocational Educational Program of Mechanical Engineering, State University of Jakarta

\section{Abstract}

The aim of this research is to improve the design of vehicles si pitung G4 UNJ for the Shell Eco-marathon Asia competition, to get reduction of aerodynamic drag so that the fuel consumption can be reduced. Aerodynamic drag reduction can be found by the reduction of aerodynamic coefficient. The improvement focused on the front wheel sparkboard vehicle body. Front wheel sparkboard was modified from the parallel side to look like fish body side form to get smooth aerodynamics flow. For drawing the

Corresponding Author: Raden Engineu radenengineu@gmail.com

Received: 11 January 2019 Accepted: 14 February 2019 Published: 25 March 2019

Publishing services provided by Knowledge E

(c) Sirojuddin et al. This article is distributed under the terms of the Creative Commons

Attribution License, which permits unrestricted use and redistribution provided that the original author and source are credited.

Selection and Peer-review under the responsibility of the 3rd ICTVET 2018 Conference Committee.

\section{G OPEN ACCESS} design, Autodesk Inventor software was used, while the aerodynamic simulation test used CFD Autodesk Flow Design Software and Solid Works Flow Software. Based on the simulation with velocity $30 \mathrm{~km} / \mathrm{h}$, test result shows for Si Pitung G4 drag coefficient $\mathrm{Cd}=0.15$ and Si Pitung $\mathrm{G} 5=0.13$. It has been found that aerodynamic drag reduction coefficient Si Pitung G5 compared to Si Pitung G4 equal to $17.77 \%$.

Keywords: aerodynamic drag reduction, vehicles, Shell Eco-marathon Asia, drag coefficient

\section{Introduction}

Reduction of vehicle aerodynamic drag is very serious issue in the last decade, especially after increasing of fossil fuel price and reduction of air pollution. Observation of vortex simulation flow around an ideal form of land vehicle at Reynold number until 105 using CFD at tail vehicle to reduce drag [1]. [2] Observe aerodynamic drag of the vehicle ARTeC's PEC 2011 EMo-C. [3] Observed how to reduce drag by firing between truck and container trailer, drag reduction can be reached until $26 \%$. Research by [4] observed by putting ellip flap ellip behind bus. Drag reduction about $11,1 \%$. Research to reduce drag by [5] that focus on effect of deflector to aerodynamic drag on rear side vehicle body of Ahmed model. Research the factors influence on the aerodynamics drag reduction of commercial vehicles [6] by add-on parts including deflector, side fenders, visor, engine 
compartment flow can reduce the value of Cd. [7] Proposed 2-D mathematical model of curve body profile shark fish to be applied at various vehicle body. Experiment results shows that aerodynamic body curve of the shark body applied to sedan-x vehicle body using CFD software shows smooth flow trajectory[8]. Drag reduction can be found by finding value of $\mathrm{Cd}$. Testing of $\mathrm{Cd}$ value, flow trajectory and pressure contour using Computational Fluid Dynamics (CFD). Focus in this research is to reduce drag vehicle si Pitung G4 for Shell Eco Marathon Asia 2015 by reducing aerodynamic drag coefficient.

\section{Methods and Equipment}

\subsection{Methods}

This research held at Design Laboratory of Mechanical Engineering State University of Jakarta using CFD Autodesk Flow Design Software to get drag coefficient Cd and Solid Works Flow Software for flow trajectory. The flow diagram as follows:

$3 \mathrm{D}$ design and dimension according to Shell regulation using Autodesk Inventor then to analyzed Cd used Software Autodesk Flow Design and for flow trajectory using Solid Works Flow simulation.

Design of vehicle body must be aerodynamic, strong, light weight and cheap price and must follow Shell regulation according to Figure 4.

Data for simulation results of software reported are coefficient Cd, flow trajectory, static pressure contour, and velocity contour.

\section{Results}

The parameter that will be analyzed are drag coefficient, flow trajectory, velocity contour, and static pressure contour. General mathematical rule to get aerodynamic drag coefficient [11, 12]:

$$
C d=\frac{2 F d}{\rho A V^{2}}
$$

where $C d$ is drag coefficient, $F d$ is drag force (pressure and skin friction drag), $\rho$ is specific mass of air, $A$ is frontal area, $V$ is speed. 


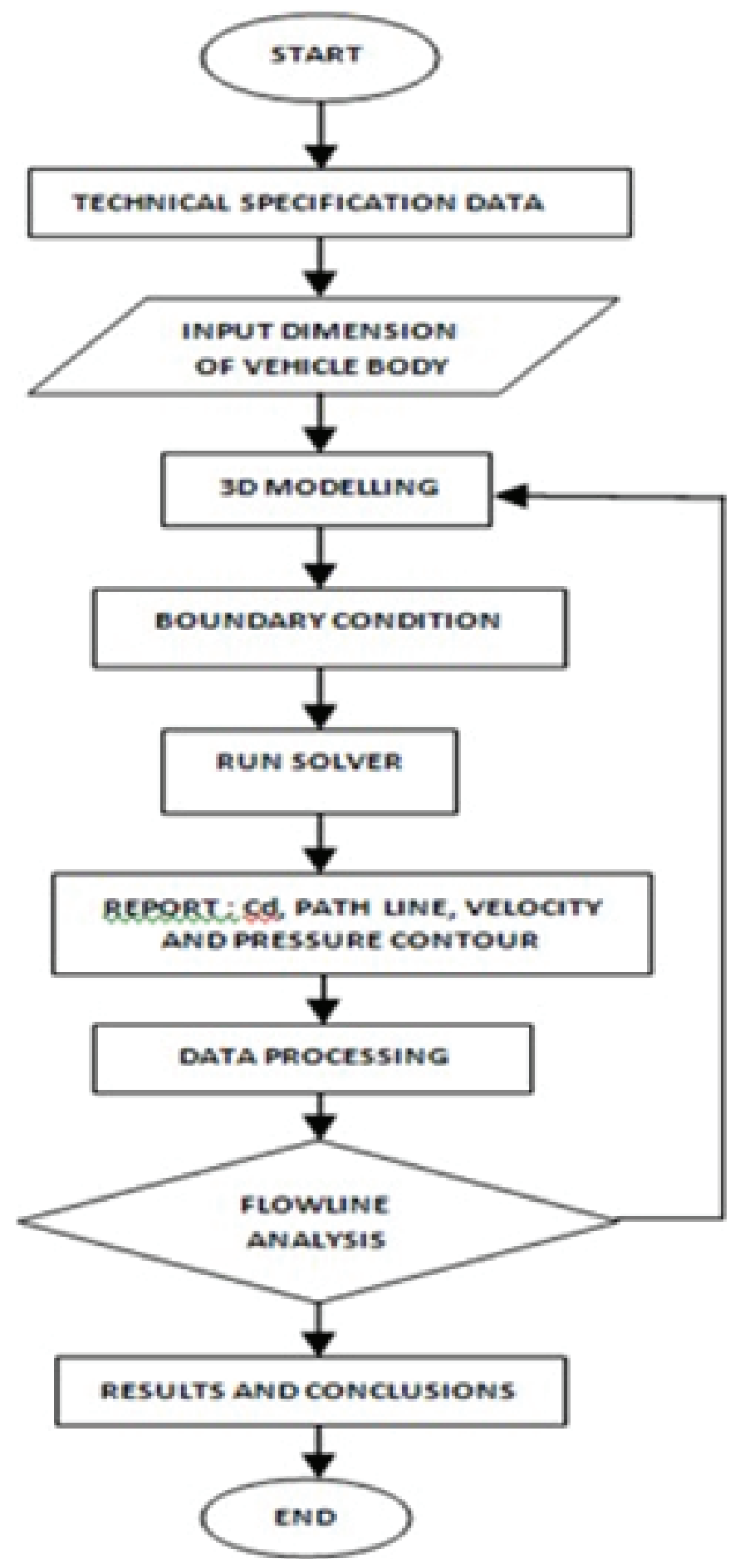

Figure 1: Flow diagram.

\subsection{Simulation results of flow trajectories}

From Figure 5a, flow trajectory of fluid seems vortex around front wheel spark board at tail body of vehicle. According to Figure 5b, flow trajectory of Si Pitung G5 is quiet good, we can see from flow line color around geometry of the body. 


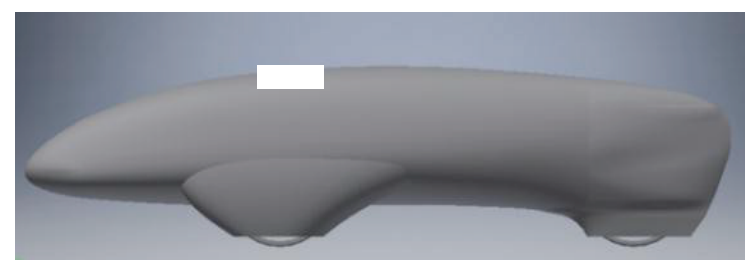

(a)

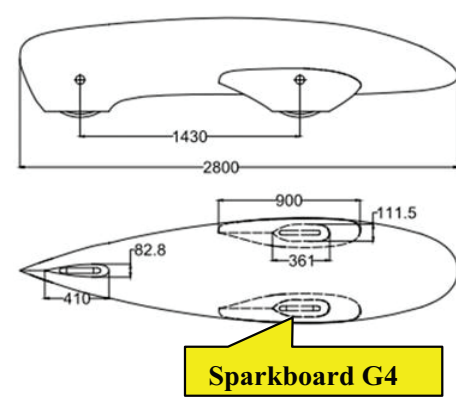

(b)

Figure 2: Si Pitung G4, 3D design (a), Side and Bottom View (b).
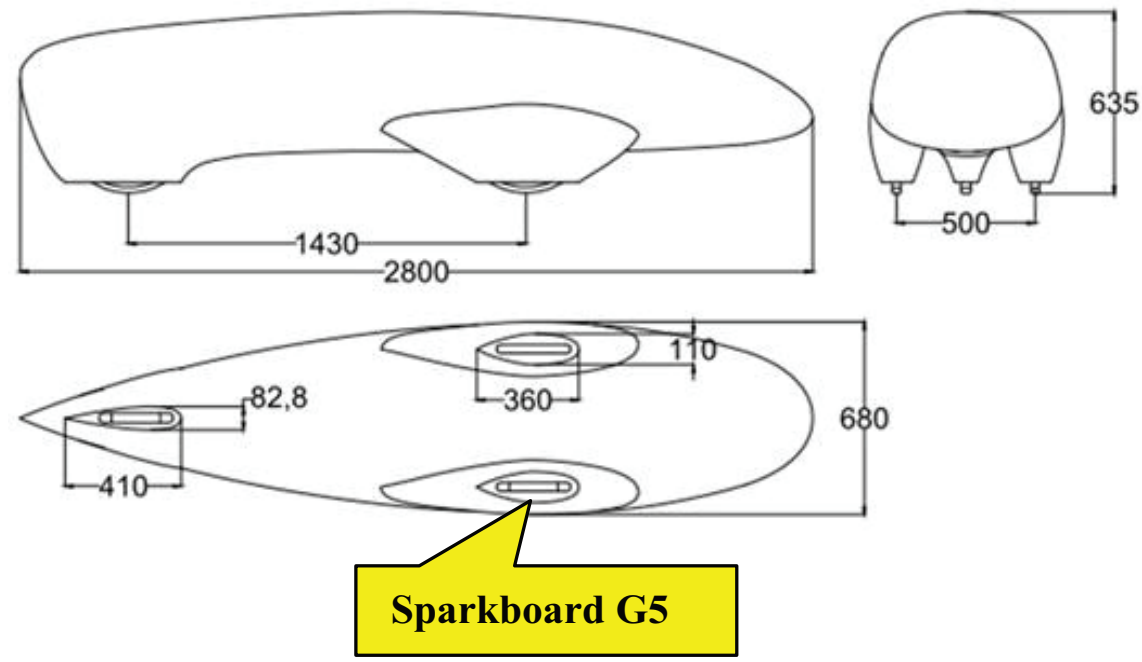

Figure 3: Front, Side and Bottom View of Si Pitung G5.

\begin{tabular}{|c|c|}
\hline Bersmater & Limiti \\
\hline inglet & $<100 \mathrm{~cm}$ \\
\hline Wuth & $4130 \mathrm{~cm}$ \\
\hline tevel & s. $350 \mathrm{~cm}$ \\
\hline Track weth & X50 om \\
\hline 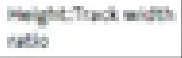 & $<128$ \\
\hline Whertilene & $10100 \mathrm{~cm}$ \\
\hline Erwer wegen & $x 50 \&$ \\
\hline Whicle wesuct & e.146/k \\
\hline
\end{tabular}

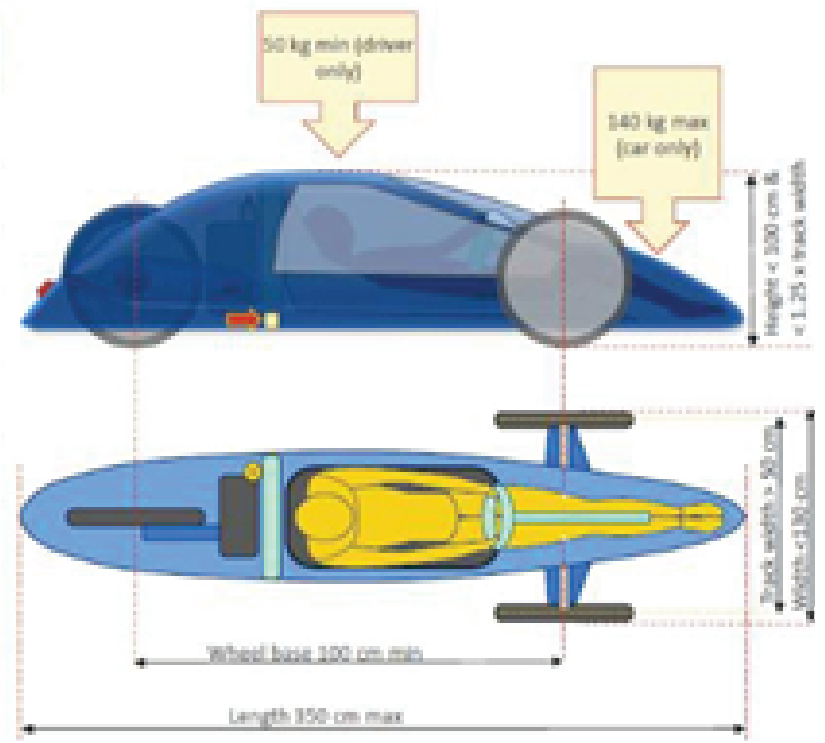

Figure 4: Shell Design Regulation [9, 10]. 


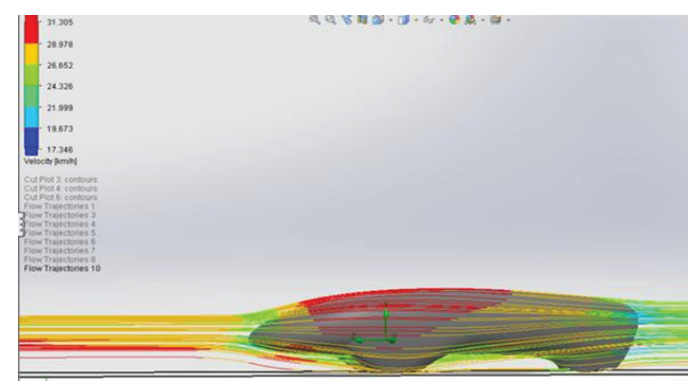

(a)

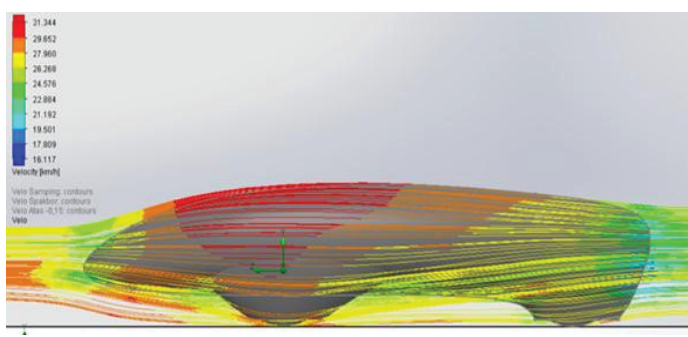

(b)

Figure 5: Flow Trajectory on Side View, Si pitung G.4 (a), Si Pitung G5 (b).

\subsection{Simulation results of static pressure}

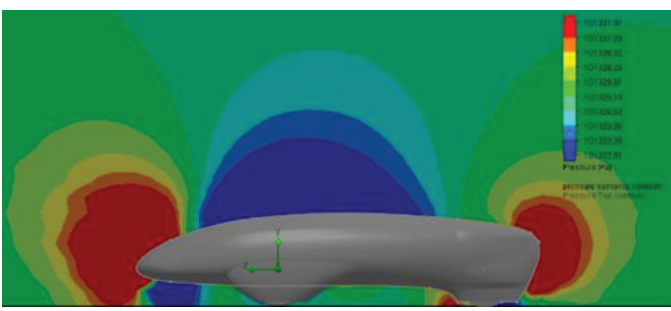

(a)

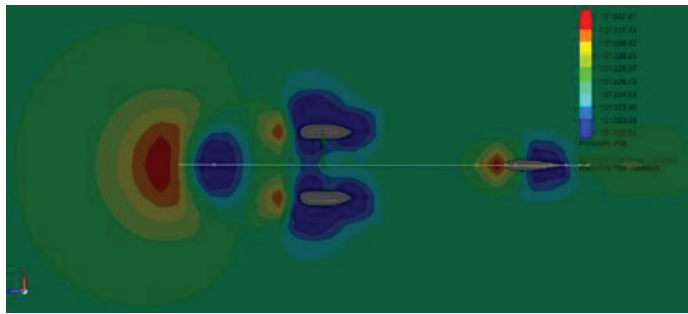

(b)

Figure 6: Pressure contour Si Pitung G 4, Side View (a), Bottom view (b).

From Figures 6(a) and 6(b), it seems that distribution of high static pressure appear in front of vehicle body by red color. Low pressure and vortex appear around spark board front wheel by blue color.

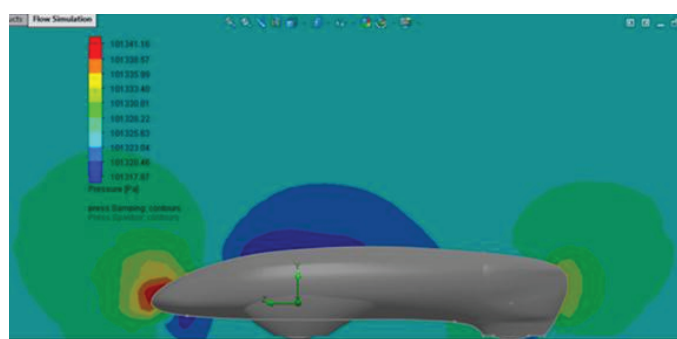

(a)

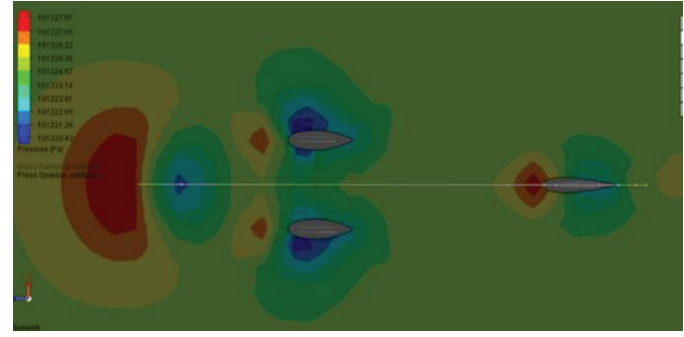

(b)

Figure 7: Pressure contour Si Pitung G 5, Side View (a), Bottom view (b).

Figures 7(a) and 7(b) shows that distribution of high static pressure appear in front of vehicle body by red color but vortex around spark board front wheel minimized by blue color. Reduced the vortex will reduced aerodynamic drag. 


\subsection{Simulation results of velocity contour}

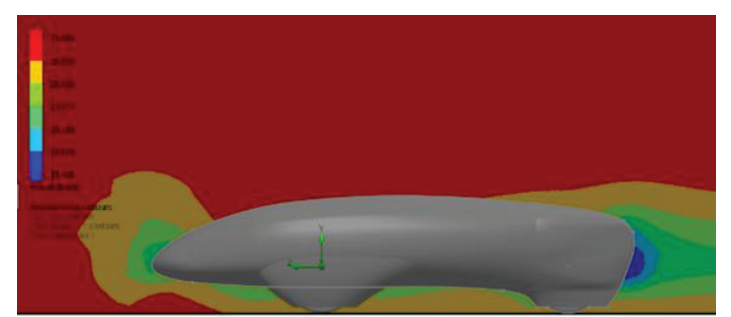

(a)

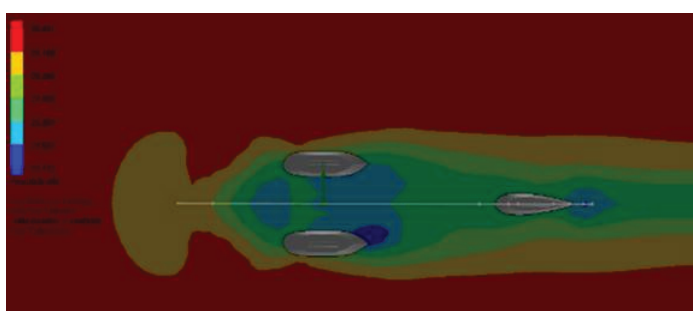

(b)

Figure 8: Velocity contour Si Pitung G4, Side View (a), Bottom view (b).

From Figures 8(a) and 8(b) seems that there is vortex around front wheel spakboard of the vehicle inside body. Vortex will increase aerodynamic drag.

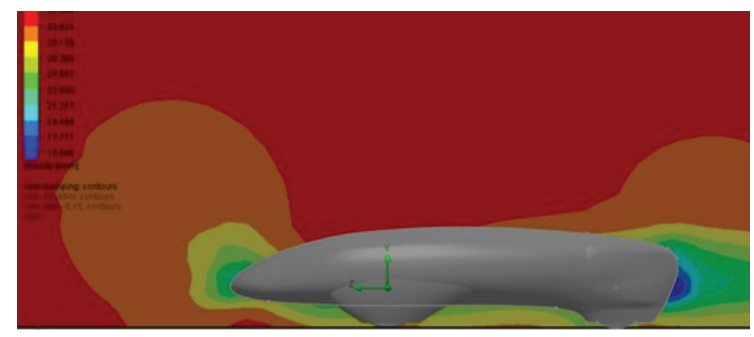

(a)

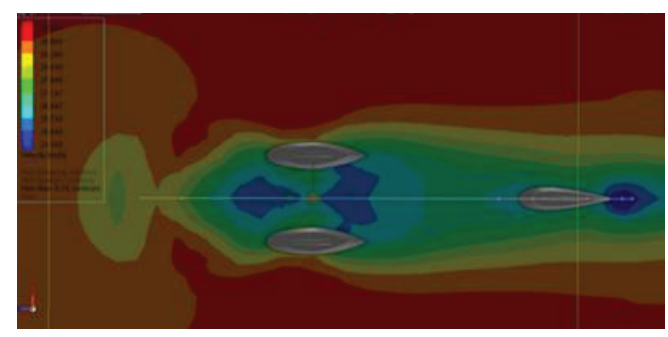

(b)

Figure 9: Velocity Contour Si Pitung G5, Side View (a), Bottom View (b).

From Figures 9(a) and 9(b), it seems that there is a flow improvement around the front wheel spark board body.

TABLE 1: Value of drag coefficient Cd.

\begin{tabular}{|l|l|l|l|c|c|c|c|} 
No. & \multicolumn{5}{|c|}{ Model } & \multicolumn{5}{|c|}{ Speed (km/h) } \\
\hline & & & $\mathbf{1 0}$ & $\mathbf{2 0}$ & $\mathbf{3 0}$ & $\mathbf{4 0}$ & $\mathbf{5 0}$ \\
\hline 1 & G4 & Cd & 0.16 & 0.15 & 0.15 & 0.15 & 0.15 \\
\hline 2 & G5 & Cd & 0.14 & 0.13 & 0.13 & 0.13 & 0.13 \\
\hline
\end{tabular}

\section{Discussion}

Reduction of aerodynamic drag can be reached by modification the form of the body to become aerodynamic form like parallel form changed to become curve form. Vortex and drop pressure on tail body must be avoided. Figure 9a and 9b are improvement points of vortex in the sparkboard vehicle body as shown in Figure 8a and 8b. From table 1 can be seen that drag coefficient will decrease when the speed is increase. 


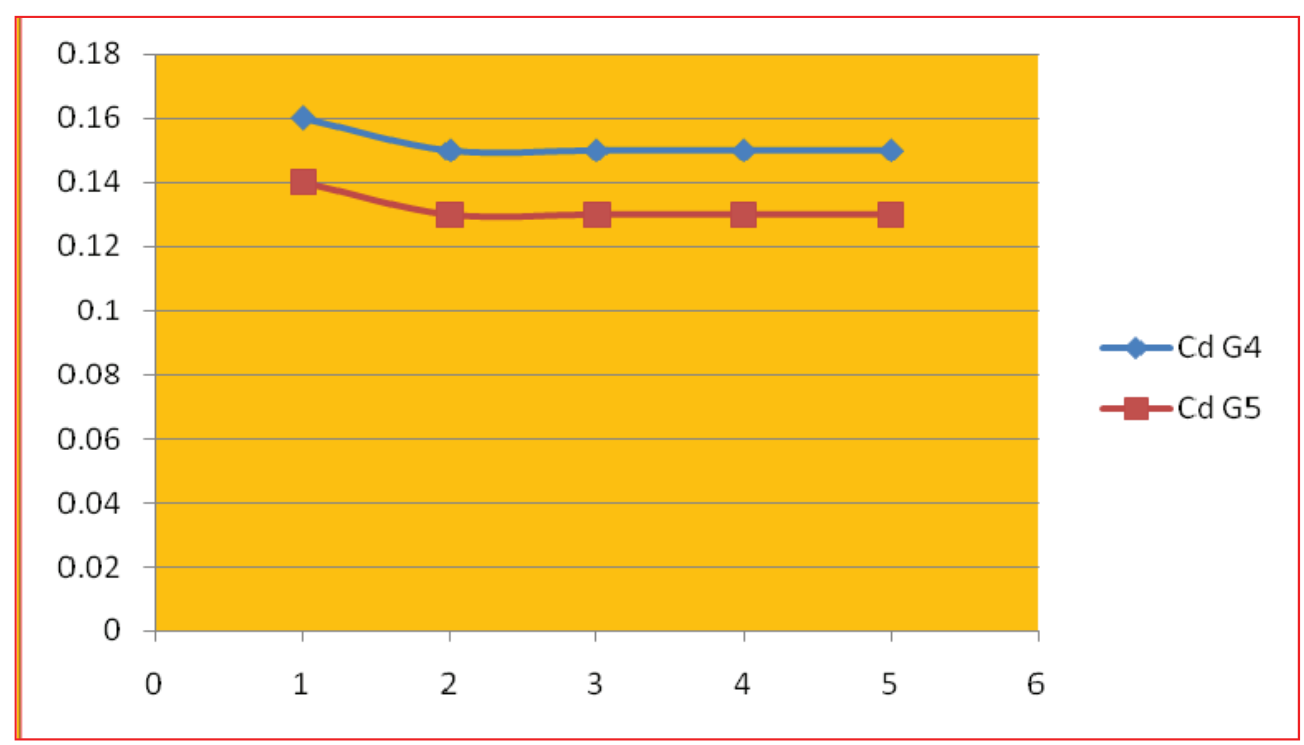

Figure 10: Value of drag coefficient Cd Si Pitung G4 and G5.

\section{Conclusion}

It has been found that improvement of the front wheel sparkboard vehicle body gives reduction of Cd, from 0.15 for Si pitung G4 to 0.13 for Si Pitung G5. The percentage reduction is $17.77 \%$.

Changing form of the front wheel sparkboard vehicle body will change pressure contour and flow trajectory. Vortex is main part to reduce aerodynamic drag.

Reduce drag automatically will reduce fuel consumption.

\section{References}

[1] Verzicco, R., Fatica, M., laccarino, G., et al. (2002). Large Eddy Simulation of Road Vehicle with Drag-Reduction Devices. Journal of American Institute of Aeronautics and Astronautics (AIAA), Vol. 40, No. 12.

[2] Nasir, R.E.M., Mohamad, F., Kasiran, R., et al. (2012). Aerodynamics of ARTeC's PEC 2011 EMo-C Car. International Symposium on Robotics and Intelligent Sensors 2012 (IRIS 2012), Procedia Engineering 41: 1775-1780.

[3] Chowdhury, H., Moria, H., Ali, A., et al. (2013). A study on aerodynamics of a semitrailer truck. 5th BSME International Conference on Thermal Engineering. Procedia Engineering. 56: 201-205.

[4] Altaf, A., Omar, A.A., Asrar, W., (2014). Passive drag of square back road vehicles. Journal of Wind Engineering and Industrial Aerodynamics. 134, pp. 30-43. 
[5] Hanfeng, W., Yu, Z., Chao, Z., et al. (2016). Aerodynamic drag reduction of Ahmed body based on deflectors. Journal of Wind Engineering and Industrial Aerodynamics. 148, pp. 34-44.

[6] Shijie, F., Qiang, F., Jialin, Z., et al. (2012). Research on Drag Reduction of Commercial Vehicle Based on Aerodynamics, in Proceedings of the FISITA 2012 World Automotive Congress, Lecture Notes in Electrical Engineering 195, SpringerVerlag Berlin Heidelberg 2013.

[7] Sirojuddin. (2014). Model Matematis 2-D Profil Lengkung Aerodinamis Badan Ikan Hiu, Prosiding Seminar Nasional Mesin dan Teknologi Kejuruan (SNMTK) Universitas Negeri Jakarta. 21 Mei 2014, Jakarta. PRC-07, pp.191-195.

[8] Sirojuddin. (2015). Uji Streamlines Profil Lengkung 2-D Badan Ikan Hiu Pada Kendaraan Mobil Sedan-X Dengan Software CFD. Prosiding Seminar Nasional Mesin dan Teknologi Kejuruan (SNMTK) Universitas Negeri Jakarta. 27 Mei, Jakarta, Indonesia. PRC-15. p. 64.

[9] Shell Eco-Marathon 2016 Official Rules. (2016). Chapter I.

[10] Shell Indonesia, http://www.shell.co.id/id/aboutshell/media-centre/news-andmedia-releases/2013/sembilan-tim-mahasiswa-menangkan-tantangan-merancangkendaraan-masa-depan.html accessed on 18th July 2016, at 10.31 WIB.

[11] Gillespie, T. D., (1992). Fundamentals of Vehicle Dynamics, 79-100. SAE Inc., Warrendale.

[12] Anderson, John. D. (2007). Fundamentals Of Aerodynamics(Fourth Edition). New York: Mc Graw Hill. 